\title{
The impact of the digital revolution on the SAJR
}

Thank you to those members of the RSSA who participated in the recent April 2013 RSSA/SAJR poll conducted to obtain a formal record indicating their preferences when accessing journal content.

Of the 213 responses, 55\% indicated a preference for a digital-only format that includes online journal access and digital applications for mobile devices. Interestingly, $45 \%$ indicated a preference for the printed journal along with either online access (21\%) or digital applications for mobile devices (24\%).

The first issue of the SAJR was published on 6 April 1963 as a supplement to the South African Medical Journal, and was recognised as the official journal of the RSSA. Issues were printed on 'special art paper, so necessary for the reproduction of radiographs' as the need for high-resolution print images was required. ${ }^{[1]}$

Today, the digital revolution aids this desire for high-resolution radiology images. The propagation of gadgets, digital applications and Web-based information has given clinicians and radiologists new methods to obtain and share information.

The proliferation of the electronic distribution of media has in the past decade been accompanied by a rapid decline in demand for print material. The American Journal of Roentgenology (AJR) has witnessed a recent shift of approximately $30 \%$ of the journal's content from print to Web exclusively. ${ }^{[2]}$ However, the printed edition of the $A J R$ continues to be delivered to $52 \%$ of current subscribers, suggesting the persistent appeal of the hard copy, even in this digital era of hand-held mobile devices. The RSSA/SAJR April 2013 poll similarly reflected a 45\% readership preference for the printed journal format.
Currently, all articles published by the SAJR are freely and permanently accessible online immediately on publication, without subscription charges or registration obstacles. The journal provides immediate open access to its content, supporting the global exchange of knowledge by making research freely available. The first available issue of the $S A J R$ that was electronically accessible on archive is Volume 8 Issue 1 (2004). Online access simultaneously provides journals with a platform to make

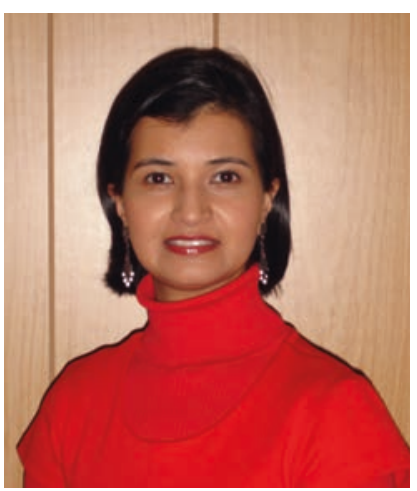
content available that cannot be included in print format because of costly page restrictions.

The SAJR intends to move in line with international trends, embracing the digital media revolution that is rapidly changing the way we approach scholarly journalism.

\section{Razaan Davis}

Editor

\footnotetext{
1. Komins C. Message from the Chairman of the Radiological Society of South Africa. S Afr Med J Suppl 1963; Vol XXXVII Jan-June.

2. Kanne JP. The digital media revolution: What it means for the AJR. AJR 2011;197:6-7. http://www. ajronline.org/doi/pdf/10.2214/AJR.10.6048 (accessed 3 August 2013).
}

S Afr J Rad 2013;17(3):83. DOI:10.7196/SAJR.939 